\title{
A contribuição do Desenvolvimento Industrial Brasileiro no contexto da Modernização Agrícola da Região Centro-Oeste
}

\author{
Danillo Alves de Oliveira ${ }^{1}$ \\ Cidonea Machado Deponti ${ }^{2}$
}

\section{Resumo}

Em síntese, este trabalho, cujo objeto de pesquisa situou-se na avaliação do contexto histórico, político e econômico que circundou o crescimento da indústria nacional, especialmente a partir das primeiras décadas do século $X X$, buscou, em primeira instância, evidenciar as principais características e contribuições que o desenvolvimento industrial no Brasil forneceu para o processo de modernização agrícola no Centro-Oeste brasileiro no decorrer da década de 1970. Concomitantemente, discutiu-se a importância do papel desempenhado pela agricultura no conjunto da evolução industrial no país. O estudo teve como ponto de partida a análise da transição de uma economia de exportação de bens primários, que culminou em um modelo de produção industrial caracterizado, inicialmente, pelo desenvolvimento da indústria de bens de consumo imediato, seguido pela produção de bens de consumo duráveis e, por fim, pelos bens de capitais e de insumos básicos, onde a participação do Estado como agente indutor deste processo tornouse decisiva.

Palavras-chaves: Produção. Desenvolvimento Industrial. Urbano-Industrial. Modernização agrícola.

\section{Abstract}

In summary, this study, whose research object stood in the evaluation of the historical, political and economic circled the growth of domestic industry, especially from the early decades of the twentieth century, aimed in the first instance to highlight the main features and contributions to industrial development in Brazil provided for the process of agricultural modernization in Central Brazil from the 1970s. Concomitantly, discussed the importance of the role played by agriculture in the overall industrial development in the country. The research was as a starting point the analysis of the transition from an export economy of primary goods, which culminated in an industrial production model initially characterized by the development of the industry of consumer goods immediately, followed by the

\footnotetext{
${ }^{1}$ Economista, Mestre e Doutorando em Desenvolvimento Regional pela Universidade de Santa Cruz do Sul (Unisc).danillocomp@hotmail.com

2 Economista, Mestre em Integração Latino-americano e Doutora em Desenvolvimento Rural. Professora do Programa de Pós-Graduação em Desenvolvimento Regional da Universidade de Santa Cruz do Sul (Unisc). cidonea@unisc.br
} 
production of durable consumer goods and capital goods by order and basic inputs, where state participation as a promoter of this process became decisive.

Keywords: Production. Industrial Development. Urban-Industrial. Agricultural modernization.

\section{Introdução}

O desenvolvimento deste trabalho de pesquisa tem por finalidade primária apresentar uma abordagem de ordem teórica e histórica dos principais elementos políticos e econômicos que resultaram no processo de modernização da atividade agrícola, no Centro-Oeste brasileiro, ao adentrar a década de 1970, cuja trajetória evoluiu pelos diversos estágios de desenvolvimento de alguns dos setores da indústria nacional, iniciados ainda nas primeiras décadas do século XX. Neste sentido, será utilizada a contribuição teórica de diversos autores, além de alguns dados censitários extraídos do Instituto Brasileiro de Geografia e Estatística (IBGE).

A princípio, o texto apresenta uma abordagem do contexto histórico do desenvolvimento industrial brasileiro, sendo abordadas as principais questões políticas e econômicas, de ordem interna e externa, que ensejaram a convergência de uma economia de exportação de bens primários para uma economia industrial.

Em sequência, a discussão volta-se para a exposição das etapas subtendidas no processo de desenvolvimento industrial brasileiro, no período compreendido entre as décadas de 1930 e 1970, sendo evidenciadas e debatidas as características produtivas da indústria nacional daquele momento. Os autores ainda mensuram e distinguem os principais ciclos e elementos econômicos desta fase.

Logo em seguida, a controvérsia estabelece-se em torno das consequências e dos desequilíbrios do setor agrícola provocados pelo desenvolvimento industrial, bem como se discute a função desempenhada pelo meio rural em prol do crescimento da indústria, demonstrando, neste instante, os pontos de convergência entre ambos os setores econômicos. Por conseguinte, é feita uma abordagem acerca da importância da participação do Estado como elemento de desenvolvimento das estruturas capitalistas e industrial do país.

E, por fim, a reflexão do texto recai para o debate que visa demonstrar a contribuição que a dinâmica de desenvolvimento industrial brasileiro exerceu sobre o 
processo de modernização agrícola, não apenas em âmbito nacional, mas, principalmente, nos estados que compõem a região do Centro-Oeste brasileiro, cujos dados apresentados visam a revelar o crescimento na adoção de máquinas, equipamentos, implementos, além da utilização de defensivos, adubos e fertilizantes químicos no desenvolvimento das atividades rurais a partir do início da década de 1970.

\section{0 contexto de desenvolvimento industrial brasileiro e suas implicações no meio agrícola}

Ainda na primeira metade do século $X X$, especialmente a partir da década de 1930, observa-se que o desenvolvimento econômico no país ocorreu paralelamente em função da necessidade da industrialização, que, por sua vez, foi incentivada por um conjunto de eventos, de ordem interna e externa, que resultaram na adoção de uma série de políticas de Estado que tinham por objetivo fomentar e estimular a produção interna de bens e serviços, através da expansão do parque industrial brasileiro.

Brum (2010) relata que, logo nas primeiras décadas do século XX, o Brasil entra em um estágio de transição de uma economia de exportação de bens primários para uma economia industrial, estimulada, inicialmente, pelo acontecimento da Primeira Guerra Mundial, ocorrida entre 1914 e 1918, acontecendo, neste período, o bloqueio internacional das transações comerciais, dificultando, dessa forma, o processo de importação e exportação de mercadorias.

Outros dois eventos, também situados na primeira metade do século $X X$, reforçaram a necessidade da industrialização da economia brasileira. O primeiro está vinculado à crise mundial de 1929, também conhecida como a Grande Depressão, ocorrida em outubro deste mesmo ano, levando à quebra a Bolsa de Valores de Nova York, refletindo de forma incisiva nas economias europeia e norteamericana. Já o segundo evento está associado com a Segunda Guerra Mundial, deflagrada entre 1939 e 1945. Todos os eventos ocorridos neste período convergiam para uma situação de restrição ao comércio internacional e, por consequência, criaram-se limitações para importação, ocasionando, desta maneira, 
uma crescente demanda do mercado interno, criando, assim, condições favoráveis ao desenvolvimento industrial do país (BRUM, 2010).

\begin{abstract}
Devido à Grande Depressão, houve uma queda no nível de renda de $25 \%$ a $30 \%$, e o índice de preços dos produtos importados subiu $33 \%$. Como consequência, a redução das importações foi da ordem de $60 \%$, baixando de $14 \%$ para $8 \%$ do produto interno. Parte da procura, antes satisfeita com importações, passou a ser atendida pela oferta interna. Com isso, a demanda interna passaria a ter importância crescente como elemento dinâmico nessa conjuntura de recessão mundial. A intensidade da procura interna criou uma situação nova, com a preponderância do setor ligado ao mercado interno no processo de formação de capital e no conjunto de investimentos no país (LACERDA et al., 2010, p. 75).
\end{abstract}

Neste contexto, Brum (2010) descreve que o desafio de promover a industrialização no Brasil estava unicamente condicionado a uma manifestação governamental, justificada essencialmente pela necessidade de investimentos em obras de infraestrutura, e dadas as circunstâncias econômicas mundiais da ocasião, o país não dispunha de capital privado suficiente para realizar as mudanças emergentes, restando ao Estado brasileiro a execução deste trabalho.

Ainda de acordo com Brum (2010), dessa forma, iniciou-se o desenvolvimento industrial no Brasil, sendo este estabelecido em três fases, cada qual com características e épocas específicas. A primeira fase foi marcada pela produção de bens de consumo imediato e se estabeleceu ainda na década de 1930, por meio da instalação de indústrias especializadas, principalmente na produção de produtos têxteis, vestuários, alimentos e bebidas. Já a segunda fase aconteceu a partir da década de 1950 e foi determinada pela produção de bens de consumo duráveis, voltada especialmente para a produção automobilística, de eletrodomésticos e eletroeletrônicos. E, por fim, a terceira fase, conhecida pela produção de bens de capital e de insumos básicos, iniciada entre as décadas de 1930 e 1940, foi responsável pela produção de petroquímicos, fertilizantes, maquinário e equipamentos; todavia, vale ressaltar que a priorização deste último segmento somente ocorreu a partir da segunda metade da década de 1960.

Entretanto, Serra (1982) menciona que o desenvolvimento industrial brasileiro ocorreu de forma retardada, mas apresentou-se sob um forte crescimento econômico, a partir da década de 1930, especialmente no período pós-guerra, cujo reflexo foi denotado em função do significativo aumento do Produto Interno Bruto 
(PIB), que, na média, cresceu acima dos 7\% ao ano entre as décadas de 1940 e 1980, sendo essencialmente consolidado pelo progresso da indústria manufatureira, destacando-se, neste contexto, os setores produtivos de bens de consumo durável e de capital.

Lacerda et al. (2010) destacam que, entre 1955 a 1962, as indústrias de bens de consumo duráveis e bens de capital apresentaram um expressivo desenvolvimento, chegando a uma taxa de crescimento média anual equivalente a $26,4 \%$ e 23,9\%, respectivamente. Entretanto, a partir de 1963, dada à instabilidade política e econômica do momento, o ritmo de crescimento industrial foi interrompido, sendo retomado somente após a segunda metade da década de 1960.

Serra (1982) acrescenta que o crescimento industrial compreendido entre as décadas de 1940 e 1980 pode ser caracterizado em quatro principais ciclos econômicos, que oscilam em momentos de auge e de declínio, conforme apresentado no Quadro 1.

\section{Quadro 1 - Principais características dos ciclos do crescimento industrial no Brasil entre 1940 e 1980.}

\begin{tabular}{ll}
\hline Períodos & Principais características \\
\hline & - Crescimento do mercado doméstico. \\
& - Protecionismo à indústria nacional e substituição das importações. \\
& - Significativa entrada de capital estrangeiro. \\
& - Incentivos, subsídios fiscais e creditícios. \\
& - Crescimento da oferta de produtos agrícolas, mesmo com baixo \\
investimento no setor. & - Atração de investimentos estrangeiros direto. \\
& - Criação da Petrobras. \\
& - Instalação das indústrias automobilística, naval, materiais elétricos \\
& pesados, máquinas e equipamentos. \\
& - Ampliação do setor siderúrgico, petrolífero e de energia elétrica; \\
& criação da Eletrobrás. \\
\hline & - Dado ao conjunto de investimentos de ordem pública e privada no \\
& período anterior, inicia-se um processo de desaceleração de \\
& natureza cíclica. \\
- Crescimento econômico lento, em torno de $2,6 \%$ ao ano. \\
- Política econômica orientada à eliminação do déficit fiscal. \\
- Significativa redução do crédito. \\
- Compressão salarial.
\end{tabular}




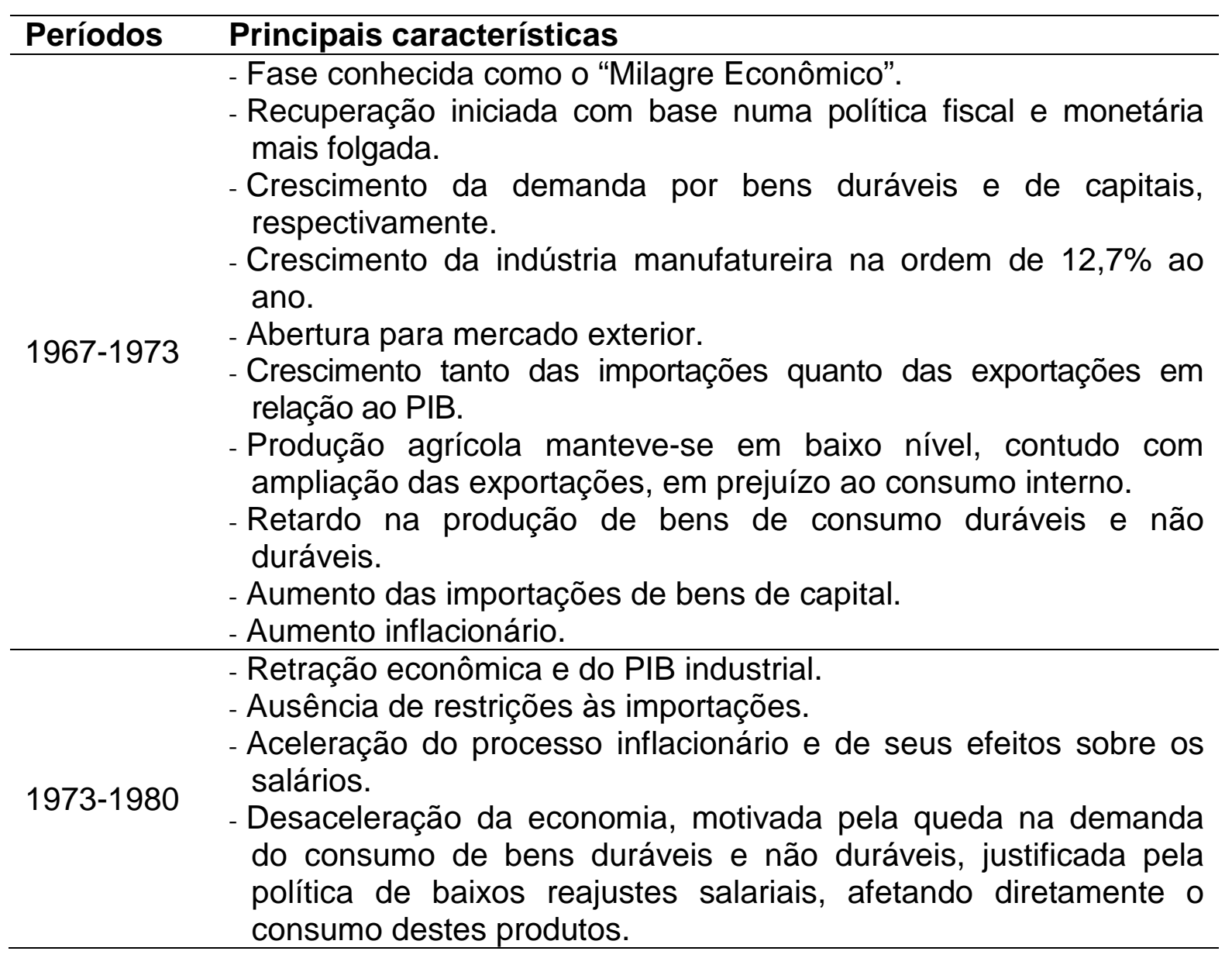

Fonte: Elaborado pelo autor com base em Serra (1982, p. 72-121).

Estevam (1998) comenta sobre os principais entraves políticos e econômicos enfrentados pela indústria na primeira metade da década de 1960:

Na medida em que a economia brasileira ingressava nos anos 1960 uma
série de problemas reclamava soluções de base, principalmente no setor
público tendo em vista a crescente importância do Estado como produtor.
Em função da maior complexidade da economia, reformas tributária,
administrativa, infraestrutural e financeira constituíam prementes
necessidades. O aumento da capacidade produtiva industrial carecia de
mecanismos de financiamento em longo prazo e da gestão de políticas de
planejamento direcionadas para o setor. Além disto, reformas de cunho
social (agrária e urbana) estiveram no âmago das discussões e o processo
desaguou no embate político entre progressistas e conservadores
culminando no golpe de 1964 (ESTEVAM, 1998, p. 157).

Todavia, a discussão sobre o assunto convergiu para o âmbito da agricultura, e, conforme coloca Serra (1982), a dinâmica de desenvolvimento industrial provocou alguns efeitos sobre o setor agrícola, como a redução da 
participação na renda interna, no conjunto total da economia brasileira, que passou de 24,9\%, em 1949, para 13,2\% em 1979. Concomitantemente, perceberam-se outros desequilíbrios, como a diminuição da população economicamente ativa e a transferência de recursos de financiamento para a manutenção da aglomeração urbana e do crescimento industrial.

No entanto, Gonçalves Neto (1997) argumenta que a estrutura agrária brasileira não mais atendia às necessidades de manutenção da estrutura urbana voltada para a industrialização, fundamentada pela existência dos latifúndios e a baixa estrutura de desenvolvimento da atividade produtiva no campo, classificada como obsoleta e com baixos ganhos de produtividade, impondo aos preços dos produtos agrícolas uma valoração maior que a dos produtos industriais, ocasionando, dessa forma, uma elevação do nível salarial para os operários instalados nas áreas urbanas.

Para Albuquerque e Nicol (1987), o meio agrícola desempenha funções relevantes ao desenvolvimento do complexo industrial brasileiro, por meio da transferência de mão de obra do campo para o chão de fábrica, fornecimento de matérias-primas e alimentos de baixo custo, formação de divisas internacionais, por intermédio das exportações, além de contribuir de forma direta na constituição de um mercado consumidor interno para os produtos industrializados, estabelecendo-se como parte do processo de crescimento econômico.

\footnotetext{
Nesse contexto o setor rural pode contribuir para a expansão do mercado interno de formas alternativas e não mutuamente exclusivas: consumir bens e serviços finais produzidos por setores urbano-industriais, empregar fertilizantes, defensivos, tratores e outros fatores de produção gerados por esses setores ou produzir alimentos e matérias-primas a preços baixos para atender à demanda dos consumidores urbanos (ACCARINI, 1987, p. 59).
}

Seguindo a análise, torna-se importante mencionar a interdependência de ambos os setores, pois o desenvolvimento industrial, do mesmo modo, exercia influência sobre o agrícola, particularmente no que se refere à oferta de máquinas e equipamentos. Neste sentido, Serra (1982) destaca que: 
Embora o setor de bens de capitais no Brasil seja mais amplo e integrado do que nos demais países da América Latina (México, por exemplo), podese dizer que apresenta uma espécie de "atraso relativo", caracterizado por insuficiente desenvolvimento tecnológico e, mais ainda, por uma reduzida participação nacional na geração da tecnologia utilizada. Existem restrições estruturais à modificação dessa situação, eliminá-la ou ao menos atenuá-la, poderá representar uma condição relevante para preservar em longo prazo o ritmo histórico de expansão da economia observado no pós-guerra (SERRA, 1982, p. 59).

Todavia, Brum (2010) menciona que, ainda no final da primeira metade da década de 1960, algumas medidas que visavam à retomada do crescimento econômico e o fortalecimento da indústria no país foram adotadas pelo Estado, sendo que tais ações baseavam-se na criação de um conjunto de programas que pudesse fornecer a base de desenvolvimento tecnológico ao processo de industrialização nacional, desdobrando-se através dos programas governamentais, dentre os quais se destacam o Fundo para aquisição de máquinas e equipamentos industriais (Finame), Fundo de democratização do capital das empresas (Fundece), Fundo de desenvolvimento técnico-científico (Funtec), Fundo de financiamento para estudos, projetos e programas (Finep), Programas de financiamento de pequenas e médias empresas (Fipeme).

No mesmo período, além das ações de incentivo ao desenvolvimento tecnológico voltado para a indústria, Lacerda et al. (2010) esclarecem que o Estado também estabeleceu mudanças de base ao sistema econômico do país, promovida através da reforma bancária, em 1965, sendo instituído o Banco Central e o Conselho Monetário Nacional; em sequência, já em 1967, ocorreu a reforma tributária.

Neste contexto, Serra (1982) destaca a importância da participação do Estado no desenvolvimento da estrutura capitalista e do processo de industrialização no país, cujas funções foram estabelecidas não apenas nos âmbitos da promoção das políticas fiscais e monetárias, da disponibilização dos bens públicos e da organização do mercado de trabalho, mas, principalmente, na articulação dos blocos de investimentos financeiros e do provimento da infraestrutura necessária à produção de insumos intermediários, destinados à industrialização pesada.

$\mathrm{Na}$ segunda metade da década de 1960, parte da produção do parque industrial brasileiro volta-se para o setor agrícola, através do crescimento da denominada indústria de base, por meio do desenvolvimento dos petroquímicos e da indústria de metais, permitindo, assim, a expansão produtiva de fertilizantes e 
defensivos químicos, bem como a fabricação de maquinários, implementos, tratores, materiais elétricos; enfim, inicia-se a instalação de unidades fabris especializadas no fornecimento de insumos agrícolas, voltadas para atender às demandas do produtor rural, que, neste momento, passa a exercer a função de consumidor (ESTEVAM, 1998).

De acordo com os dados apresentados pelo IBGE (2013c), entre as décadas de 1960 e 1970, o crescimento de estabelecimentos industriais no Brasil foi à ordem de $48,77 \%$, saltando de 110.771 unidades fabris para 164.793 , destacando-se, neste contexto, principalmente os ramos industriais de produtos de materiais plásticos, mecânica, materiais elétricos e comunicação, borracha e metalúrgica, respectivamente. Tais segmentos apresentaram uma expressiva variação de crescimento, conforme observado na Tabela 1.

Tabela 1 - Variação do número de unidades industriais por ramo de atividade entre as décadas de 1960 e 1970.

\begin{tabular}{lccc}
\hline $\begin{array}{l}\text { Unidades industriais por ramo } \\
\text { de atividade }\end{array}$ & $\begin{array}{c}\text { Unidades } \\
\text { industriais em } \\
\mathbf{1 9 6 0}\end{array}$ & $\begin{array}{c}\text { Unidades } \\
\text { industriais em } \\
\mathbf{1 9 7 0}\end{array}$ & $\begin{array}{c}\text { Variação no } \\
\text { período (\%) }\end{array}$ \\
\hline Produtos de materiais plásticos & 295 & 1.311 & 344,41 \\
Mecânica & 1.692 & 6.744 & 298,58 \\
Material Elétrico e comunicação & 982 & 3.155 & 221,28 \\
Borracha & 339 & 974 & 187,32 \\
Metalúrgica & 4.850 & 9.681 & 99,61 \\
Extração de minerais & 2.178 & 3.906 & 79,34 \\
Diversas & 2.218 & 3.755 & 69,30 \\
Editorial e gráfica & 3.389 & 5.526 & 63,06 \\
Mobiliário & 8.160 & 13.127 & 60,87 \\
Material de Transporte & 2.096 & 3.319 & 58,35 \\
Bebidas & 3.044 & 4.798 & 57,62 \\
Papel e Papelão & 764 & 1.178 & 54,19 \\
Química & 1.774 & 2.645 & 49,10 \\
Produtos de minerais não & 18.146 & 25.367 & 39,79 \\
metálicos & 33.534 & 46.815 & 39,60 \\
Produtos alimentares & 11.196 & 14.812 & 32,30 \\
Madeira & 4.272 & 5.309 & 24,27 \\
Têxtil & & & \\
Vestuário calçado e artefatos de & 7.639 & 8.613 & 12,75 \\
tecidos & & & \\
Produtos farmacêuticos e & 504 & 522 & 3,57 \\
veterinários & 1.071 & 1.060 & $-1,03$ \\
Perfumaria sabão e velas & 2.350 & 2.032 & $-13,53$ \\
Couros peles e similares & 278 & 144 & $-48,20$ \\
Fumo & $\mathbf{1 1 0 . 7 7 1}$ & $\mathbf{1 6 4 . 7 9 3}$ & $\mathbf{4 8 , 7 7}$ \\
\hline Total & & &
\end{tabular}

Fonte: IBGE (2013c), adaptado pelo autor. 
Dado ao conjunto de elementos de ordem política e econômica, conforme anteriormente discutido, nota-se que importantes segmentos da indústria, vinculados ao desenvolvimento da atividade rural, apresentaram significativo crescimento, no decorrer da década de 1960, tornando-se um fator preponderante no processo de modernização agrícola, que essencialmente ocorreria nas décadas seguintes.

\section{Os reflexos da dinâmica industrial na modernização agrícola do centro oeste brasileiro}

Os efeitos da dinâmica industrial, ocorrida no Brasil entre as décadas de 1930 e 1960, somados à aplicação de um conjunto de políticas de Estado direcionadas ao setor agrícola, como, por exemplo, o crédito rural e os investimentos em pesquisa e extensão, que não serão abordados neste artigo, provocaram efeitos, no início da década de 1970, por meio do emprego de tecnologias no desenvolvimento das atividades rurais, evidenciadas principalmente pelo crescimento da utilização de maquinários e implementos, fertilizantes e defensivos químicos.

Bacha (2004) comenta sobre a importância do processo de modernização agrícola no país a partir da segunda metade década de 1960 :

Os anos de 1965 a 1986 constituíram um período de aceleração do
processo de modernização da agropecuária brasileira, o qual foi
impulsionado por diversas políticas direcionadas a estimular o crescimento
deste setor. Houve mudanças na importância da agropecuária no processo
de desenvolvimento do país, o que levou à alteração no desempenho de
algumas funções normalmente atribuídas à agropecuária no processo de
desenvolvimento de uma nação (BACHA, 2004, p. 155).

Neste sentido, Gonçalves Neto (1997) relembra que, durante a década de 1960, o embate político sobre o modelo de desenvolvimento rural brasileiro esteve alicerçado sobre dois pilares, sendo o primeiro relacionado com a questão da reforma agrária, sob o argumento que tal instrumento consentiria aos trabalhadores maior acesso ao fator de produção terra. O segundo consistia no raciocínio da modernização da agricultura, voltado especialmente para atender à demanda do complexo urbano-industrial, por meio do crescimento incremental do quantitativo produtivo, concebida através de investimentos em tecnologia agrícola e efetivada pela adoção do uso de fertilizantes, defensivos, mecanização e orientação técnica. 
Santo (2001) reforça que o emprego de tecnologia no campo, inicialmente, esteve associado aos fatores que levam, em primeira instância, ao ganho de produtividade e qualidade no desenvolvimento da atividade agrícola, mas, por conseguinte, determinam a redução dos custos produtivos, tornando-se um importante instrumento na produção de bens de consumo com custos menores.

Sendo assim, ao adentrar a década de 1970, o país já contava com o número de 4.924.019 estabelecimentos agrícolas, dos quais 253.132 localizavam-se na região Centro-Oeste, sendo 145.115 destes em Goiás ${ }^{3}$. Observa-se também que o número total de pessoas ocupadas no desenvolvimento das atividades rurais, no território nacional, equivalia a um número superior a 17 milhões e meio de pessoas (IBGE, 2013b).

A adoção de tecnologia agrícola no desenvolvimento das atividades rurais, no período compreendido entre 1970 e 1985, pode ser demonstrada pelo crescimento do número de tratores, arados e fertilizantes químicos utilizados dentro da fazenda, conforme os dados apresentados nas Tabelas 2, 3, e 4.

Tabela 2 - Comparação regional dos estabelecimentos agrícolas que utilizavam maquinário em 1970.

\begin{tabular}{lccc}
\hline Maquinário agrícola & Brasil & Centro-Oeste & Goiás \\
\hline Tratores & 165.870 & 10.340 & 5.692 \\
Arados de tração mecânica & 160.884 & 9.612 & 5.818 \\
Máquinas utilizadas no plantio & - & - & - \\
Máquinas utilizadas na colheita & 98.184 & 2.931 & 1.575 \\
\hline Totais & $\mathbf{4 2 4 . 9 3 8}$ & $\mathbf{2 2 . 8 8 3}$ & $\mathbf{1 3 . 0 2 5}$ \\
\hline
\end{tabular}

Fonte: IBGE (2013b), adaptado pelo autor.

Tabela 3 - Comparação regional dos estabelecimentos agrícolas que utilizavam maquinário em 1985.

\begin{tabular}{lccc}
\hline Maquinário agrícola & Brasil & Centro-Oeste & Goiás \\
\hline Tratores & 665.280 & 85.233 & 33.548 \\
Arados de tração mecânica & 585.698 & 71.916 & 29.459 \\
Máquinas utilizadas no plantio & 342.066 & 40.891 & 17.961 \\
Máquinas utilizadas na colheita & 110.420 & 14.257 & 4.674 \\
\hline Totais & $\mathbf{1 . 7 0 3 . 4 6 4}$ & $\mathbf{2 1 2 . 2 9 7}$ & $\mathbf{8 5 . 6 4 2}$ \\
\hline
\end{tabular}

Fonte: IBGE (2013a), adaptado pelo autor.

\footnotetext{
${ }^{3}$ Goiás: No período mencionado, o espaço territorial de Goiás abrangia os atuais estados de Goiás e Tocantins.
} 
Com base nos dados apresentados nas tabelas 2 e 3, é possível fazer uma análise mais abrangente sobre o nível de adoção de máquinas e implementos agrícolas no desenvolvimento das atividades rurais. Nota-se que, no período analisado, o crescimento do número de tratores no Brasil correspondeu a 301,09\%, os arados de tração mecânica, a $264,05 \%$, e as máquinas utilizadas na colheita esboçaram uma variação de $12,46 \%$.

\section{Tabela 4 - Comparação regional do número de estabelecimentos agrícolas que empregavam fertilizantes químicos no período compreendido entre 1970 e 1985.}

\begin{tabular}{lccc}
\hline Regiões & $\begin{array}{c}\text { Número de } \\
\text { estabelecimentos } \\
\text { em 1970 }\end{array}$ & $\begin{array}{c}\text { Número de } \\
\text { estabelecimentos } \\
\text { em 1985 }\end{array}$ & $\begin{array}{c}\text { Variação no } \\
\text { período (\%) }\end{array}$ \\
\hline Brasil & 425.667 & 1.510 .640 & 254,89 \\
Centro-Oeste & 6.903 & 94.673 & $1.271,48$ \\
Goiás & 5.807 & 68.997 & $1.088,17$ \\
\hline
\end{tabular}

Fonte: IBGE (2013b) e IBGE (2013a), adaptados pelo autor.

Observa-se que, no mesmo período, a região Centro-Oeste apresentou um crescimento bem acima da média a nacional. A variação do número de tratores nesta região equivaleu a $724,30 \%$, os arados de tração mecânica, a $648,19 \%$, e as máquinas utilizadas na colheita alcançaram uma variação de 386,42\%. Em Goiás, nota-se também uma evolução superior ao desempenho da média do país, exprimindo um aumento na proporção de 489,39\%, 406,34\% e 196,76\%, respectivamente.

Outro dado importante também analisado refere-se à utilização de fertilizantes químicos. Neste caso, nota-se que o crescimento do número de estabelecimentos agrícolas que utilizaram esse tipo de tecnologia apresenta-se ainda maior na região Centro-Oeste, quando comparado ao índice de crescimento nacional, demonstrando uma variação superior a $1.200 \%$. Esta mesma situação também pode ser observada no Estado de Goiás, onde a presença deste insumo agrícola esteve associada a um crescimento superior a $1.000 \%$ no mesmo período.

Estevam (1998) relata que a diferença entre a agricultura tradicional e a moderna, no Centro-Oeste brasileiro, passou a ser evidenciada a partir da década de 1970, surgindo, assim, um novo modelo de estabelecimento agrícola, 
caracterizado por uma série de mudanças estruturais, baseadas na utilização de tecnologia agrícola, fundada essencialmente na utilização intensiva do solo, no uso de insumos e maquinários agrícolas, cuja produção destina-se principalmente para comercialização, fornecendo elementos necessários à especialização produtiva.

\section{Considerações finais}

O objeto central de análise deste estudo situou-se em torno da discussão teórica acerca das principais contribuições que o desenvolvimento industrial no Brasil forneceu ao processo de modernização agrícola, especialmente aquele ocorrido na região Centro-Oeste do Brasil, a partir da década de 1970. Neste contexto, verificaram-se alguns pontos que foram de fundamental importância para o andamento deste decurso.

O primeiro, identificado logo no começo do século $X X$, refere-se ao período em que o modelo de desenvolvimento econômico do país passou por uma fase de transição, convergindo gradativamente de um estágio de exportação de bens primários para uma etapa caracterizada pela produção industrial, instituída pelo crescimento da indústria nacional, a partir da década de 1930, e evidenciada inicialmente através da ampliação produtiva dos bens de consumo imediato e não duráveis, seguida pelos bens de consumo duráveis e, por último, e talvez o mais importante no conjunto da modernização agrícola, os bens de capitais e insumos básicos, sendo este segmento responsável pela produção de máquinas e equipamentos, metalurgia, petroquímicos, fertilizantes, dentre outros.

Neste enfoque, verificou-se também a interdependência entre ambos os setores, agrícola e industrial, e, conforme foi discutido no texto, averiguou-se que, dentro do processo de industrialização, o meio rural exerceu um importante papel em prol do crescimento da indústria, através do fornecimento de matérias-primas e alimentos de baixo custo, transferência de mão de obra, inclusive para a formação de um mercado interno para o consumo dos produtos industrializados. Todavia, a contrapartida da indústria apresentou-se nas etapas seguintes, por meio da oferta de máquinas, equipamentos e insumos necessários ao desenvolvimento da atividade agrícola. 
E, por último, destacou-se a importância da participação do Estado no conjunto do crescimento da produção industrial e do processo de modernização agrícola, efetivado, a princípio, pelo alto volume de investimentos realizados, principalmente em obras de infraestrutura e na produção de insumos básicos, exercendo, neste momento, a função de agente do desenvolvimento das estruturas capitalistas no país. Em sequência, notou-se uma forte presença na condução das políticas voltadas para o fortalecimento institucional, como o fomento aos programas de desenvolvimento tecnológico e científico, e a regulamentação do sistema financeiro.

E, por fim, conclui-se que os resultados obtidos pela dinâmica de desenvolvimento industrial, entre as décadas de 1930 e 1960, principalmente no que se referiu à indústria de bens de capitais e insumos básicos, tornaram-se fatores preponderantes ao processo de modernização agrícola na década de 1970, particularmente para os estados da região do Centro-Oeste brasileiro, que, em conformidade com os dados demonstrados, apresentaram um crescimento na adoção de máquinas, equipamentos e utilização de fertilizantes químicos acima da média observada em âmbito nacional.

\section{Referências}

ACCARINI, José Honório. Economia rural e desenvolvimento: reflexões sobre o caso brasileiro. Petrópolis: Vozes, 1987.

ALBUQUERQUE, Marcos Cintra Cavalcanti de; NICOL, Robert. Economia agrícola: o setor primário e a evolução da economia brasileira. São Paulo: McGraw-Hill, 1987.

BACHA, Carlos José Caetano. Economia e política agrícola no Brasil. São Paulo: Atlas, 2004.

BRUM, Argemiro Jacob. O desenvolvimento econômico brasileiro. 27. ed. ljuí: Unijuí, Petrópolis: Vozes, 2010.

ESTEVAM, Luís. O tempo da transformação: estrutura e dinâmica da formação econômica de Goiás. Goiânia: Do Autor, 1998.

GONÇALVES NETO, Wenceslau. Estado e agricultura no Brasil: política agrícola e modernização econômica brasileira 1960-1980. São Paulo: Hucitec, 1997. 
IBGE. Instituto Brasileiro de Geografia e Estatística. Censo Agropecuário Brasil 1985. Disponível em: <http://biblioteca.ibge.gov.br/visualizacao/monografias/ GEBIS\%20-20RJ/censoagropecuario/Censo\%20Agropecuario_1985_BR.pdf>. Acesso em: 28 jan. 2013a.

. Instituto Brasileiro de Geografia e Estatística. Censo Agropecuário Brasil 1970. Disponível em: <http://biblioteca.ibge.gov.br/visualizacao/monografias/ GEBIS\%20\%20RJ/censoagropecuario/Censo\%20Agropecuario_1970_BR.pdf>. Acesso em: 28 jan./2013b.

. Instituto Brasileiro de Geografia e Estatística. Censo Industrial Brasil 1970. Disponível em: <http://biblioteca.ibge.gov.br/visualizacao/monografias/GEBIS\%20$\% 20 R J / c e n s o i n d u s t r i a l / C e n s 0 \% 20$ Industrial_1970_BR.pdf>. Acesso em: 28 jan. 2013c.

LACERDA, Antônio Corrêa et al. Economia Brasileira. 4. ed. São Paulo: Saraiva, 2010.

SANTO, Benedito Rosa Espírito. Os caminhos da agricultura brasileira. São Paulo: Evoluir, 2001.

SERRA, José. Ciclos e Mudanças Estruturais na Economia Brasileira do PósGuerra. In: BELLUZZO, Luiz Gonzaga de Melo; COUTINHO, Renata (Orgs.). Desenvolvimento Capitalista no Brasil: Ensaios sobre a Crise. São Paulo: Brasiliense, 1982. p. 56-121. 